\title{
Correction to: The Search for Invariance: Repeated Positive Testing Serves the Goals of Causal Learning
}

Elizabeth Lapidow and Caren M. Walker

\section{Correction to:}

Chapter 10 in: J. B. Childers (ed.), Language and Concept Acquisition from Infancy Through Childhood, https://doi.org/10.1007/978-3-030-35594-4_10

In the original version of this book, Chapter 10 was inadvertently published without separation between acknowledgment and the quote in the chapter opening page. This has now been updated in this revised version. 